\title{
The Awareness of Abdominal Obesity and Metabolic Syndrome in Healthcare Workers
}

\author{
Melike Ozcelik ${ }^{\mathrm{a}}$, Mehmet Uzunlulua, b, Muhammed Kizilgul ${ }^{\mathrm{a}}$, \\ Aytekin Oguz ${ }^{\mathrm{a}}$, Tebil Antika
}

\begin{abstract}
Background: In a study that has been done five years ago, it was reported that too few of healthcare workers were aware of abdominal obesity and metabolic syndrome (MetS) as a clinical entity. The aim of this study was to evaluate if any difference in abdominal obesity and MetS awareness in healthcare staff working in the same hospitals was occurred in the past 5 years.
\end{abstract}

Methods: A total of 731 healthcare workers (physicians: 262, nurses: 199 , other healthcare staff: 270 , mean age: $32.17 \pm 8.0$ ) were enrolled. Demographic, anthropometric, and biochemical data were recorded. International Diabetes Federation (IDF) criteria were used for abdominal obesity and MetS assessment.

Results: The frequency of abdominal obesity and awareness of abdominal obesity was $32.5 \%$ (36.6\% in women, $29.7 \%$ in men, $\mathrm{P}=$ $0.050)$ and $16.7 \%$ (18.7\% in physicians, $9.6 \%$ in nurses, $3.8 \%$ in other healthcare staff, $\mathrm{P}=0.001)$ respectively. The awareness of MetS as a clinical entity was $31.3 \%$ (78.6\% in physicians, $11.1 \%$ in nurses, $0.4 \%$ in other healthcare staff, $\mathrm{P}=0.001)$. The frequency of MetS was $6.1 \%(3.7 \%$ in women, $10 \%$ in men, $\mathrm{P}=0.015)$.

Conclusions: In this research, it has been found out that for the past five years, still very few of the healthcare workers are aware of the MetS and abdominal obesity as a clinical entity.

Keywords: Abdominal obesity; Metabolic syndrome; Healthcare workers; Awareness

Manuscript accepted for publication June 14, 2013

${ }^{a}$ Medeniyet University, Goztepe Training and Research Hospital, Department of Internal Medicine, Istanbul, Turkey

${ }^{\mathrm{b}}$ Corresponding author: Mehmet Uzunlulu, Rasimpasa District, Meltem

Street, Tamer Apartment, No: 10, Flat: 5, Kadikoy, Istanbul, Turkey.

Email: mehmetuzunlulu@yahoo.com

doi: http://dx.doi.org/10.4021/jem176w

\section{Introduction}

Metabolic Syndrome (MetS) is a cluster of risk factors in $\neg$ cluding abdominal obesity, hypertension, atherogenic dyslipidemia, hyperglycemia, prothrombotic and proinflammatory status, and an important risk factor for atherosclerotic cardiovascular diseases and type 2 diabetes mellitus [1]. It is being stated that the awareness about obesity and MetS that are nowadays being regarded as a global issue of public healthcare, is remarkably low $[2,3]$. In a study that has been done five years ago, it was reported that too few of healthcare workers were aware of abdominal obesity and MetS as a clinical entity [4]. The aim of this study was to evaluate if any difference in abdominal obesity and MetS frequency in healthcare staff working in the same hospitals was occurred in the past 5 years.

\section{Material and Method}

A total of 731 healthcare workers above 20 years (physicians: 262 , nurses: 199 , other healthcare staff: 270 , mean age: $32.17 \pm 8.0$ ) working in Medeniyet University Goztepe Training and Research Hospital, Siyami Ersek Thoracic and Cardiovascular Surgery Training and Research Hospital, and Sureyyapasa Chest Diseases and Thoracic Surgery Training and Research Hospital clinics, outpatient clinics and laboratories were enrolled in the study. Approval of the local ethics committee (approval date and no: 01.09.2011/25) and informed consent of the participants were received for the study. The study was conducted in accordance with the Declaration of Helsinki.

\section{Study design}

Information on demographics, comorbid diseases, smoking and alcohol habits and drugs used were obtained for all individuals who met inclusion criteria and gave consent, and their anthropometric measurements and biochemical data were recorded.

Criteria proposed by International Diabetic Federation 
(IDF) were used for the diagnosis of MetS and abdominal obesity: waist circumference $>94 \mathrm{~cm}$ (male) or $>80 \mathrm{~cm}$ (female) and presence of at least two of the following: blood pressure $\geq 130 / 85 \mathrm{mmHg}$ (or use of antihypertensive medication); fasting plasma glucose $\geq 100 \mathrm{mg} / \mathrm{dL}$ (or use of antidiabetic medication); fasting triglyceride $\geq 150 \mathrm{mg} / \mathrm{dL}$ or medical treatment for high levels of triglyceride; HDL cholesterol $<40 \mathrm{mg} / \mathrm{dL}$ (male) or $<50 \mathrm{mg} / \mathrm{dL}$ (female), or medical treatment for low HDL cholesterol levels [5].

In order to determine the level of awareness of the criteria for diagnosing abdominal obesity, following question was used: What are the cut-off values for waist circumference to diagnose abdominal obesity? A response giving correct cut-off values for IDF system were considered positive. However, for either diagnosing system, both upper and lower limits should be correct.

Following questions were asked for the awareness of MetS: Have you ever heard about a disease entity called metabolic syndrome? What are the criteria for its diagnosis? A response was considered positive if the subject answers the first question as 'yes' and can list at least three of the IDF criteria.

\section{Anthropometric and biochemical evaluations}

Blood pressure was measured on both arms of the patient in a seated position after at least 10 minutes of a relaxation period, using an appropriate sphygomanometer based on the Korotkoff Phase I and Phase V sounds. A second measurement was performed on the arm with higher blood pressure. A mean value was calculated from these two systolic and diastolic blood pressure determinations with at least 3 minutes of interval. The waist circumference was measured at the narrowest point of waist in the midway between spina iliaca anterior superior and lower rib margin in light expirium when the patient was standing. The body mass index (BMI) was calculated by dividing the body weight in kilograms by height in square meters $\left(\mathrm{kg} / \mathrm{m}^{2}\right)$. Results of triglycerides, HDL cholesterol, fasting blood glucose measurements (components of MetS) made within the last 3 months were evaluated.

\section{Statistical analysis}

NCSS (Number Cruncher Statistical System) 2007 and PASS 2008 Statistical Software (Utah, USA) was used for statistical analyses. In addition to descriptive statistical methods (mean, standard deviation), Oneway Anova test was used for comparison of quantitative data between groups in comparing parameters with normal distribution, and Tukey's HDS test was used for determination of the group that was significantly different than others. Intergroup comparisons of parameters with normal distribution were made with the Student's t test. Qui-square test was used for comparison

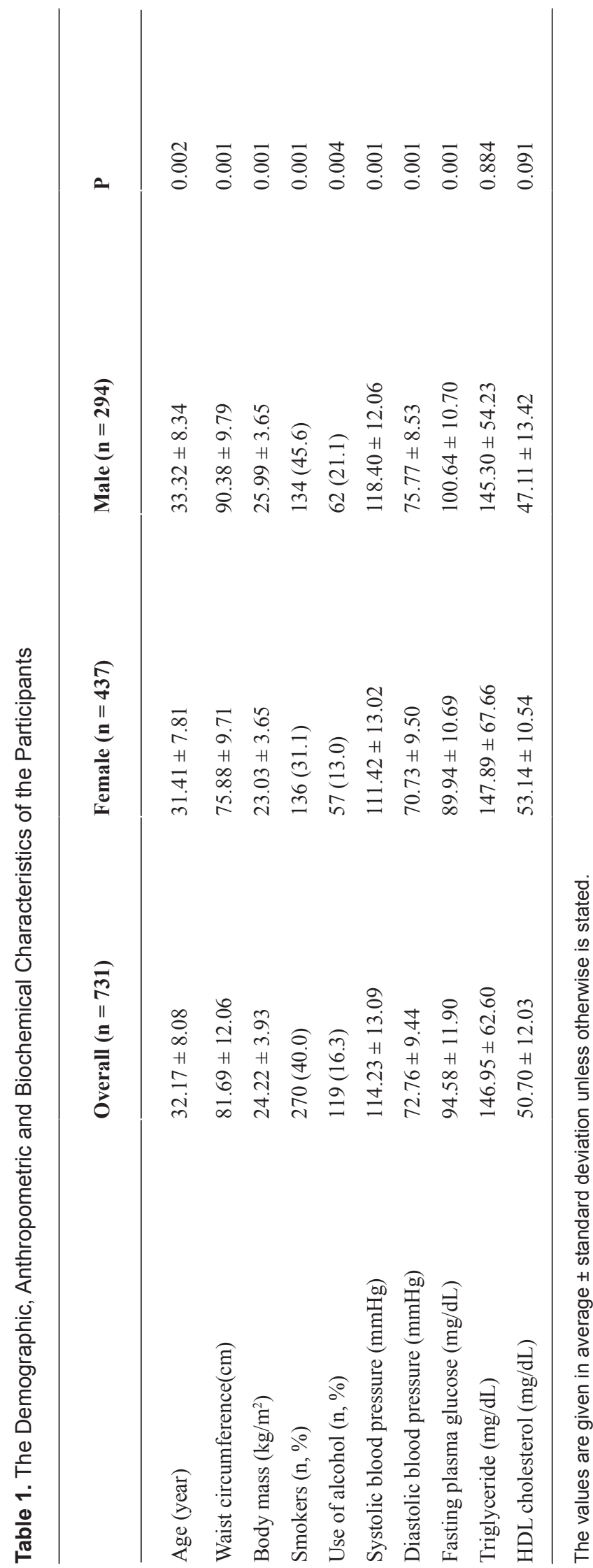




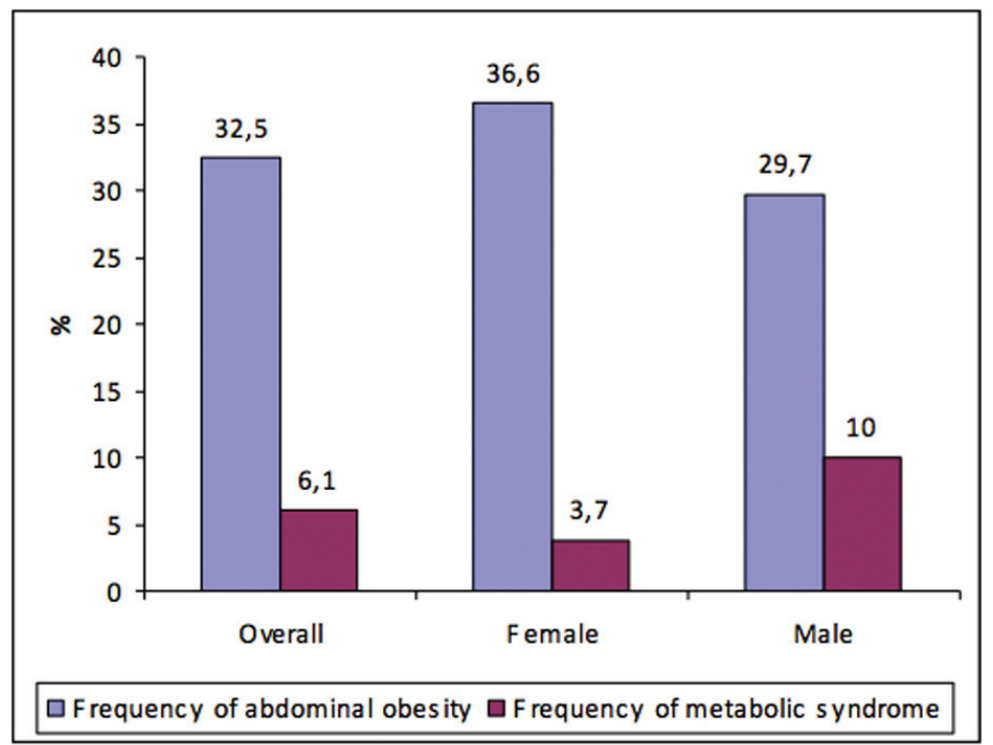

Figure 1. The frequency of abdominal obesity and metabolic syndrome according to the gender.

of qualitative data. Results were evaluated at a significance level of $\mathrm{P}<0.05$.

\section{Results}

A total of 731 healthcare workers (physicians: 262, nurses: 199 , other healthcare staff: 270 , mean age: $32.17 \pm 8.0$ ) were included in the study. Demographic and clinical characteristics of study subjects are shown in Table 1. Age, waist circumference, BMI, systolic blood pressure, diastolic blood pressure, fasting plasma glucose, frequency of smoking and alcohol were higher in males than in females in men $(\mathrm{P}<$ 0.01 for all).

The frequency of abdominal obesity and MetS are presented in Figure 1. The frequency of abdominal obesity was higher in females than in males $(36.6 \%$ in women, $29.7 \%$ in men, $\mathrm{P}=0.050$ ). The frequency of MetS was higher in males than in females ( $3.7 \%$ in women, $10 \%$ in men, $\mathrm{P}=0.015)$.

The awareness of abdominal obesity and MetS are presented in Figure 2. Awareness of abdominal obesity and MetS were $16.7 \%$ (18.7\% in physicians, $9.6 \%$ in nurses, $3.8 \%$ in

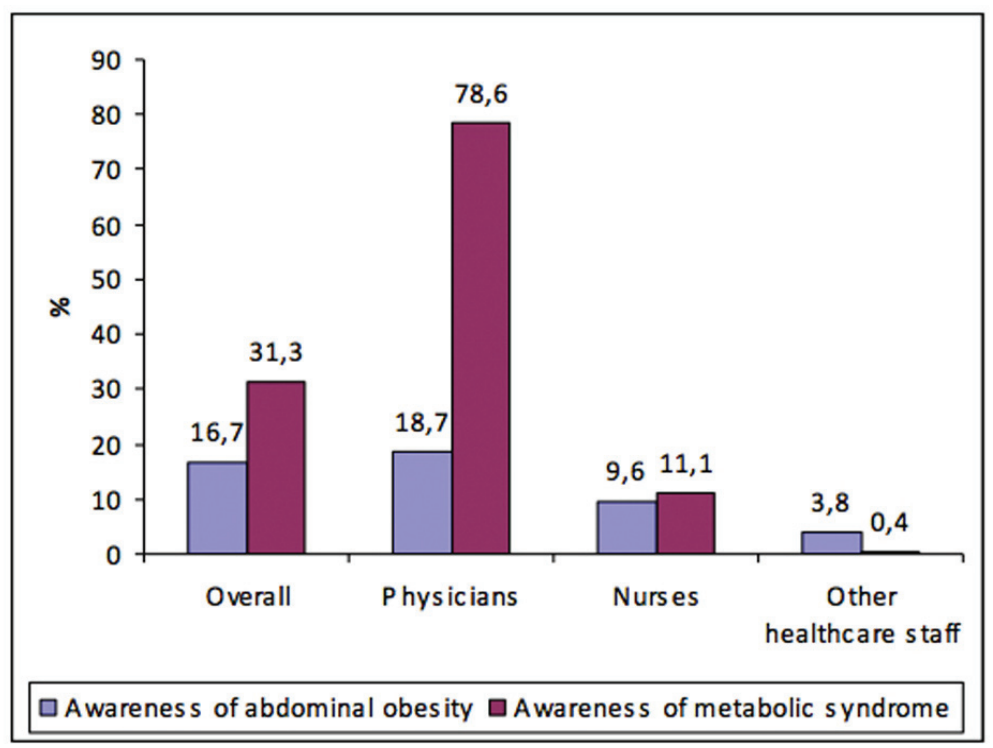

Figure 2. The awareness of abdominal obesity and metabolic syndrome. 
other healthcare staff, $\mathrm{P}=0.001)$ and $31.3 \%(78.6 \%$ in physicians, $11.1 \%$ in nurses, $0.4 \%$ in other healthcare staff, $\mathrm{P}=$ 0.001 ), respectively.

\section{Discussion}

In this research, it has been found that for the past five years, still very few of the healthcare workers are aware of the MetS and abdominal obesity.

It is stated that approaching MetS as a clinic entity and increasing the awareness on this concern would be helpful to diagnose those who are at high risk of type 2 diabetic and atherosclerotic cardiovascular diseases and, equally useful to maintain a common protective approach [6]. Besides this, it is known that the awareness of the healthcare workers, as well as the awareness of the common society, about MetS and on the related abdominal obesity is fairly low $[2,3]$. In 2006, Oguz A et al [4] researched on the awareness of healthcare workers on abdominal obesity and MetS and these were reported to be $12.9 \%$ ( $11.8 \%$ doctors, $1.2 \%$ nurses, $0 \%$ other healthcare workers) and 33.2\% (57.5\% doctors, 9.7\% nurses, $1.9 \%$ other healthcare workers). In present study which had been carried out in the same health institution in the last five years, it was aimed to examine whether or not there has been a difference in the awareness levels on the abdominal obesity and MetS. As a result it was found that the healthcare workers' awareness about the abdominal obesity had scaled up from $12.9 \%$ to $16.7 \%$, whereas the awareness about MetS decreased from $33.2 \%$ to $31.3 \%$. When it is investigated according to the fields of profession, the awareness levels of doctors, nurses and other healthcare workers about the abdominal obesity had increased, while the awareness levels of doctors and nurses on MetS had increased; and the awareness levels of other healthcare staff had decreased.

What would be the possible reason of the remarkably low level of awareness on Mets and abdominal obesity even among the healthcare workers? In order to diagnose MetS and abdominal obesity, different organizations are suggesting varied diagnose criteria and these differences arise from the diagnose criteria as well as the diagnosing of these criteria [7-11]. For example, in some of the diagnoses of MetS, the glucose intolerance and/or insulin resistance [7-9] or, abdominal obesity [5] are considered to be the exact criteria for diagnose, while in other diagnoses $[10,11]$ an obligatory element is not compulsory and three criteria out of five is accepted to be sufficient for the diagnose. The guidance notes on the diagnose criteria do not exactly agree on a common point. For example, for the diagnose of abdominal obesity, as being the most important component of MetS, the cut-off values for the waist circumference are stated to be 102/88 $\mathrm{cm}$ and $94 / 80 \mathrm{~cm}$ (men/women) respectively in the guidance notes $[5,10]$ of the IDF and Third Adult Treatment Panel. On the other hand, nowadays it is suggested to find out the waist circumference values of each population [12].

The fact that the awareness level of abdominal obesity and MetS in the last five years is still fairly low might be because of a confusion which arises from the differencing in commenting on MetS and abdominal diagnose and on the diagnose criteria.

MetS and abdominal obesity are accepted to be a global pandemic $[13,14]$. Oguz A et al [4] have found out low values in their research when compared to the generally population, these were the frequency of Mets in healthcare workers being $7.9 \%$ (5.2\% in women, $12.7 \%$ in men); the frequency of abdominal obesity in healthcare workers as $32.4 \%$ (26\% in women, $42.7 \%$ in men). In this research, when it is compared to the previous research, it can be seen that there is a decrease in the frequency of MetS (from $7.9 \%$ to $6.1 \%$ ) whereas there is no difference in the frequency of abdominal obesity. The fact that both of the frequencies of MetS and abdominal obesity are fairly lower than the common population might be linked to the verity that the population that had been collaborated with is younger and there is an environment of active working.

\section{Conclusion}

MetS and obesity, especially abdominal obesity, are important issues for the public health both in the developed and developing countries. Epidemiologic studies show that the awareness of MetS in general population is low. In this research, it has been seen that the awareness of both MetS and abdominal obesity is low even in the healthcare workers. Increasing the awareness of healthcare workers about MetS and abdominal obesity will help the individuals in the society to be kept informed and in addition, will help to reduce the risk of the development of the illnesses in the future such as type 2 diabetic and atherosclerotic cardiovascular illnesses.

\section{References}

1. Grundy SM, Brewer HB, Jr., Cleeman JI, Smith SC, Jr., Lenfant C. Definition of metabolic syndrome: Report of the National Heart, Lung, and Blood Institute/American Heart Association conference on scientific issues related to definition. Circulation. 2004;109(3):433-438.

2. Nadas J, Putz Z, Jermendy G, Hidvegi T. Public awareness of the metabolic syndrome. Diabetes Res Clin Pract. 2007;76(1):155-156.

3. Athyros VG, Ganotakis ES, Bathianaki M, Monedas I, Goudevenos IA, Papageorgiou AA, Papathanasiou A, et al. Awareness, treatment and control of the metabolic syndrome and its components: a multicentre Greek study. Hellenic J Cardiol. 2005;46(6):380-386.

4. Oguz A, Sagun G, Uzunlulu M, Alpaslan B, Yorulmaz E, Tekiner E, Sariisik A. Frequency of abdominal obe- 
sity and metabolic syndrome in healthcare workers and their awareness levels about these entities. Turk Kardiyol Dern Ars. 2008;36(5):302-309.

5. Alberti KG, Zimmet P, Shaw J. Metabolic syndrome-a new world-wide definition. A Consensus Statement from the International Diabetes Federation. Diabet Med. 2006;23(5):469-480.

6. Zimmet P, Magliano D, Matsuzawa Y, Alberti G, Shaw J. The metabolic syndrome: a global public health problem and a new definition. $\mathrm{J}$ Atheroscler Thromb. 2005;12(6):295-300.

7. World Health Organization Department of Noncommunicable Disease Surveillance. Definition, diagnosis and classification of diabetes mellitus and its complications: report of a WHO consultation. Part 1: diagnosis and classification of diabetes mellitus. Geneva, Switzerland: World Health Organization, 1999.

8. Balkau B, Charles MA. Comment on the provisional report from the WHO consultation. European Group for the Study of Insulin Resistance (EGIR). Diabet Med. 1999;16(5):442-443.

9. Einhorn D, Reaven GM, Cobin RH, Ford E, Ganda OP, Handelsman Y, Hellman R, et al. American College of Endocrinology position statement on the insulin resistance syndrome. Endocr Pract. 2003;9(3):237-252.
10. Executive Summary of The Third Report of The National Cholesterol Education Program (NCEP) Expert Panel on Detection, Evaluation, And Treatment of High Blood Cholesterol In Adults (Adult Treatment Panel III). JAMA. 2001;285(19):2486-2497.

11. Grundy SM, Cleeman JI, Daniels SR, Donato KA, Eckel RH, Franklin BA, Gordon DJ, et al. Diagnosis and management of the metabolic syndrome: an American Heart Association/National Heart, Lung, and Blood Institute Scientific Statement. Circulation. 2005;112(17):2735-2752.

12. Alberti KG, Eckel RH, Grundy SM, Zimmet PZ, Cleeman JI, Donato KA, Fruchart JC, et al. Harmonizing the metabolic syndrome: a joint interim statement of the International Diabetes Federation Task Force on Epidemiology and Prevention; National Heart, Lung, and Blood Institute; American Heart Association; World Heart Federation; International Atherosclerosis Society; and International Association for the Study of Obesity. Circulation. 2009;120(16):1640-1645.

13. Grundy SM. Metabolic syndrome pandemic. Arterioscler Thromb Vasc Biol. 2008;28(4):629-636.

14. Swinburn BA, Sacks G, Hall KD, McPherson K, Finegood DT, Moodie ML, Gortmaker SL. The global obesity pandemic: shaped by global drivers and local environments. Lancet. 2011;378(9793):804-814 